\title{
OPEN Enhancing removal efficiency of anionic dye (Cibacron blue) using waste potato peels powder
}

\begin{abstract}
Kahina Bouhadjra ${ }^{1,2}$, Wahiba Lemlikchi ${ }^{1,3 凶}$, Azedine Ferhati ${ }^{4 \bowtie}$ \& Samuel Mignard ${ }^{5}$
In the present study, the potato peel waste (PP) was used for the removal of the anionic dye Cibacron Blue P3R from an aqueous solution, activated with phosphoric acid (PPa) and calcined at $800^{\circ} \mathrm{C}$ (PPC). The materials were characterized by Scanning Electron Microscope, Energy dispersive X-ray analysis and Fourier Transform Infrared Spectroscopy. The effects of various experimental parameters $(\mathrm{pH}$, dye concentration, contact time) were also studied. The experimental results have shown that PPc has a greater capacity compared to pp and ppa. The capacity of PP bio-char (PPc) is $270.3 \mathrm{mg} \mathrm{g}^{-1}$ compared to PP $\left(100 \mathrm{mg} \mathrm{g}^{-1}\right)$ and PPa $\left(125 \mathrm{mg} \mathrm{g}^{-1}\right)$. Equilibrium experiments at $180 \mathrm{~min}$ for all materials were carried out at optimum pH (2.2): 76.41, 88.6 and 94\% for PP, PPa and PPc respectively; and the Langmuir models agreed very well with experimental data. The ability of sorbent for the sorption of CB dye follows this order: calcined $>$ activated $>$ native materials. Potato peel biochar (PPC) can be considered a promising adsorbent for removing persistent dyes from water.
\end{abstract}

The increasing use of dyes in modern industries such as food, plastics, rubber, textile and cosmetics has raised environmental concerns about their stability to light and oxidizing agents. This has encouraged intensive research for inexpensive and easily available adsorbents to remove these pollutants from water.

One of these major problems is the generation of large amounts of colored wastewaters from textile dyeing. These dyes are synthetics and can be classified into diverse groups: acidic, reactive, direct, basic and azoic. Anionic dyes include reactive dyes, direct dyes and acid dyes, which can cause severe organic and color pollution in the water environment. Therefore, their removal by sorption or other process is a necessity for the protection of the environment.

There are conventional methods for removing dyes from wastewater such as coprecipitation ${ }^{1-7}$ and electrochemical techniques 8,9 .

Biosorption, can be defined as the ability of biological materials to accumulate textile dyes from wastewater through metabolically mediated or physicochemical pathways of uptake ${ }^{10-14}$.

This work presents an investigation of the use of agriculture residues of potato peels (PP) for adsorption of an anionic dye CB (Reactive blue 49 or Cibacron blue P3R), species present in the wastewaters from textile industries. This biomass is activated using phosphoric acid to enhance its adsorption efficiency. The bio-char is prepared at $800{ }^{\circ} \mathrm{C}$ under inert media. Optimal operating conditions were examined in this work. Indeed, the extent of adsorption was considered as a function of the $\mathrm{pH}$ of the solution, the contact time and the initial dye concentration.

\section{Materials and methods}

Adsorbate. Reactive blue 49 or Cibacron blue P3R (CB) was the anionic dye used in this study. It was supplied by DBK textile industry (Algeria) and used without any purification. The structure of Blue Cibacron (BC), and the chemical characteristics are consolidated in Table 1.

Colored solutions were prepared by dissolving required quantity of $\mathrm{CB}$ in distilled water to produce a stock solution of $1000 \mathrm{mg} \mathrm{L}^{-1}$ with a $\mathrm{pH} \sim 6.5$. Adsorption studies for the evaluation of $\mathrm{PP}$ adsorbent for the removal of $\mathrm{CB}$ dye from aqueous solutions were carried out in a series of $100 \mathrm{~mL}$ flasks using a batch contact adsorption method. The concentrations of dye was determined from its characteristic UV-Vis absorbance with the

\footnotetext{
${ }^{1}$ Laboratory of Applied Chemistry and Chemical Engineering (LCAGC), University of Tizi-Ouzou, Tizi-Ouzou, Algeria. ${ }^{2}$ High National School of Public Works (ENSTP), El Kouba, Algiers, Algeria. ${ }^{3}$ University of Algiers 1 , Algiers, Algeria. ${ }^{4}$ Laboratory Chemistry and Environmental Chemistry (LCCE), University of Batna 1, Batna, Algeria. ${ }^{5}$ Institute of Chemistry of Environments and Materials of Poitiers (IC2MP), Poitiers, France. ${ }^{\square}$ email: w.lemlikchi@gmail.com; azeddine.ferhati@univ-batna.dz
} 


\begin{tabular}{|l|}
\hline \\
\hline Chemical name
\end{tabular}

Table 1. Chemical structure and general characteristics of Cibacron blue CB.

calibration method. UV-Vis spectrophotometer Shimadzu/Model UV-1601PC was used for measurement of absorbance of CB solutions at $\lambda_{\max }=625 \mathrm{~nm}$.

Adsorbents. Potato peels (Solanum tuberosum), supplied as wastes from restaurants, were cut into smaller pieces, thoroughly washed with tap water and left in open air for several days and then dried at $70{ }^{\circ} \mathrm{C}$. The peels were crushed and milled into different particle sizes in the range of $0.08-0.63 \mathrm{~mm}$. the potato peels powder (PP) was washed several times with distilled water until the wash water $\mathrm{pH}$ became identical to that of the distilled water (nearly 7). Resulting PP, was kept in glass bottles for use in the adsorption study. Chemical activation of the dry biomass was carried out using $\mathrm{H}_{3} \mathrm{PO}_{4}$ acid (analytical grade putity $\geq 98 \%$ ). $25 \mathrm{~g}$ of dry potato powder precursor impregnated with $250 \mathrm{~mL}$ of $1 \mathrm{M}$ solutions of $\mathrm{H}_{3} \mathrm{PO}_{4}$ at room temperature and kept under stirring for $18 \mathrm{~h}$. The powder was washed abundantly with distilled water to a constant $\mathrm{pH}$ and then dried at $105^{\circ} \mathrm{C}$, to constant weight (for about $24 \mathrm{~h}$ ). During the modification process, the dried activated biomass (PPa) was modified structurally by large quantities of new functional groups and new adsorption sites, which could increase the adsorption capacity. We employed dry potato powder to produce (PPc) with steam as a physical activation agent. The experiments were performed in two stages; i.e. the pyrolysis was performed in a quartz reactor at $800^{\circ} \mathrm{C}$ for $60 \mathrm{~min}$ under nitrogen flow $\left(15 \mathrm{~mL} \mathrm{~min}{ }^{-1}\right)$ and a heating rate of $27^{\circ} \mathrm{C} / \mathrm{min}$, and then the physical activation of char was performed $\left(800{ }^{\circ} \mathrm{C}\right)$ for $30 \mathrm{~min}$ under steam flow $\left(10 \mathrm{~g} \mathrm{~min}^{-1}\right)$. Pyrolysis was conducted in a tube furnace (PROTHERM PTF 12/75/600 Model).

Elemental analyses of potato peels powder (PP) was performed using organic elemental analyzer (CHONSFLASH 2000 Themo Scientific). The surface functional groups were determined automatically using a titration method. Potentiometric measurements were taken with an automatic titrator (Titrino plus 848, Metrhm), $0.1 \mathrm{~g}$ of the PP was placed in $75 \mathrm{~mL}$ of $\mathrm{NaNO}_{3}$ solution $\left(0.01 \mathrm{~mol} \mathrm{~L}^{-1}\right)$ as a supporting electrolyte and stirred overnight. The solution was titrated with $\mathrm{NaOH}\left(0.1 \mathrm{~mol} \mathrm{~L}^{-1}\right)$ under $\mathrm{N}_{2}$ saturation. The titration was carried out over a wide range of $\mathrm{pH}$. The total $\mathrm{Q}_{\text {surf }}\left(\mathrm{mmol} \mathrm{g}^{-1}\right)$, was determined as a function of $\mathrm{pH}$ by a numerical program SAIEUS (Solution of Adsorption Integral Equation Using Spline) after fitting. The morphology of the PP adsorbent was investigated using SEM images obtained from a (HITACHI SC-2500 model). The elemental compositions was analyzed by EDX (energy dispersive X-ray analysis). The thermogravimetric analyses (DTG) of the PP adsorbent were conducted using about $10 \mathrm{mg}$ of the materials, under a nitrogen atmosphere from 25 to $700^{\circ} \mathrm{C}$ in an SDT 2960 thermoanalyzer. FTIR spectra were recorded in the spectral range $4000-500 \mathrm{~cm}^{-1}$ on a ThermoNickel 6700 FTIR spectrometer. Buffered solutions at $\mathrm{pH} \sim 2.2$ were used since the adsorption of anionic dyes is maximum at this $\mathrm{pH}$ value ${ }^{15}$.

The adsorption kinetic experiments were performed by batch procedures in a thermostat shaker (120 oscillations per min.) at $25 \pm 0.1^{\circ} \mathrm{C}$, using $20 \mathrm{mg} \mathrm{L}^{-1}$ in aqueous dye solutions. This concentration was chosen to verify the performance of the materials in removing $\mathrm{CB}$ dye from diluted aqueous solutions. After $4 \mathrm{~h}$ of agitation, equilibrium condition was attained and samples were taken and filtered to determine concentration of the dye left in the solution with the aid of UV-Vis spectrophotometer at maximum wavelength $\lambda_{\max }=625 \mathrm{~nm}$. The adsorption capacity $\mathrm{q}\left(\mathrm{mg} \mathrm{g}^{-1}\right)$ and percentage removal were obtained using (Eq. 1$)$ and (Eq. 2) respectively:

$$
\begin{gathered}
\mathrm{q}_{\mathrm{e}}=\frac{\left(\mathrm{C}_{0}-C_{t}\right) \times \mathrm{V}}{\mathrm{m}} \\
\text { \% Removel }=\frac{\mathrm{C}_{0}-C_{t}}{\mathrm{C}_{0}} \times 100
\end{gathered}
$$

where $\mathrm{C}_{0}$ and $C_{t}\left(\mathrm{mg} \mathrm{l}^{-1}\right)$ are the adsorbate concentrations at the initial time and at a given time $\mathrm{t}$, respectively. $\mathrm{V}$ is the experimental volume expressed in liters and $\mathrm{m}$ is the adsorbent mass expressed in grams. 
Effect of initial $\mathrm{pH}$. The effect of the initial $\mathrm{pH}$ on removal of $\mathrm{CB}$ dye was investigated at different $\mathrm{pH}$ values $\left(2,4,6,8\right.$ and 10). The initial concentration of $\mathrm{CB}$ was fixed to $30 \mathrm{mg} \mathrm{L}^{-1}$ and adsorbent dose of $2 \mathrm{~g} \mathrm{~L}^{-1}$ for (PP and PPa), and of $0.6 \mathrm{~g} \mathrm{~L}^{-1}$ for (PPc). The samples were shaken for $2 \mathrm{~h}$ in a thermostat shaker at $25 \pm 0.1{ }^{\circ} \mathrm{C}$.

Kinetic study. Kinetic experiments were performed by mixing $2 \mathrm{~g} \mathrm{~L}^{-1}$ of (PP and $\mathrm{PPa}$ ) and $0.6 \mathrm{~g} \mathrm{~L}^{-1}$ of PPc, with $50 \mathrm{~mL}$ of dye solution $\left(\mathrm{C}_{0}=30 \mathrm{mg} \mathrm{L}^{-1}\right)$. The suspensions were shaken for $180 \mathrm{mn}$ at $\mathrm{pH}=2.2$ (optimum $\mathrm{pH}$ found as will be discussed later) in a thermostat shaker at $25 \pm 0.1^{\circ} \mathrm{C}$. Samples were collected at fixed intervals (5 min-180 min). The experimental kinetic data were fitted to two kinetic models; pseudo-first ${ }^{16}$ (Eq. 3 ) and second $\operatorname{order}^{17}$ (Eq. 4).

$$
\begin{gathered}
\ln \left(\mathrm{q}_{\mathrm{e}}-q_{t}\right)=\ln \left(\mathrm{q}_{\mathrm{e}}\right)-\frac{\mathrm{K}_{1}}{2,303} t \\
\frac{t}{q_{t}}=\frac{1}{\mathrm{k}_{2} \mathrm{q}_{\mathrm{e}}^{2}}+\frac{1}{\mathrm{q}_{\mathrm{e}}} t
\end{gathered}
$$

where $q_{t}$ is the amount of dye sorbed $\left(\mathrm{mg} \mathrm{g}^{-1}\right)$ at a given time, $\mathrm{k}_{1}\left(\mathrm{~min}^{-1}\right)$ and $\mathrm{k}_{2}\left(\mathrm{~g} \mathrm{mg}^{-1} \mathrm{mn}^{-1}\right)$ are the first and second-order-rate constants of sorption, respectively.

Effect of initial dye concentration-isotherms. The effect of the initial dye concentration on equilibrium was observed by mixing $2 \mathrm{~g} \mathrm{~L}^{-1}$ of $\mathrm{PP}$ and $\mathrm{PPa}, 0.6 \mathrm{~g} \mathrm{~L}^{-1}$ of PPc with $50 \mathrm{~mL}$ of dye solutions of varying initial concentrations $\left(\mathrm{C}_{0}=10-300 \mathrm{mg} \mathrm{L}^{-1}\right)$. The suspensions were shaken for $4 \mathrm{~h}$ at optimum $\mathrm{pH}$ in a thermostat shaker at $25 \pm 0.1^{\circ} \mathrm{C}$. The experimental equilibrium data were fitted to the Langmuir (Eqs. 5, 6) ${ }^{18}$, and Freundlich (Eq. 7) ${ }^{19}$ :

$$
\begin{gathered}
\text { Langmuir I } \frac{1}{q_{e}}=\frac{1}{\mathrm{q}_{\max }}+\frac{1}{\mathrm{q}_{\max } \cdot \mathrm{K}_{\mathrm{L}} \cdot C_{e}} \\
\text { Langmuir II } \frac{C_{e}}{q_{e}}=\frac{1}{\mathrm{q}_{\max } \mathrm{K}_{\mathrm{L}}}+\frac{C_{e}}{\mathrm{q}_{\max }} \\
\operatorname{Ln}_{q_{e}}=\frac{1}{\mathrm{n}} \operatorname{Ln} C_{e}+\mathrm{LnK}_{\mathrm{f}}
\end{gathered}
$$

where $\mathrm{q}_{\max }\left(\mathrm{mg} \mathrm{g}^{-1}\right)$ is the maximum amount of adsorption; $\mathrm{K}_{\mathrm{L}}\left(\mathrm{L} \mathrm{mg}^{-1}\right)$ is the Langmuir adsorption equilibrium constant. $\mathrm{K}_{\mathrm{f}}$ and $1 / \mathrm{n}$ were the constants; $\mathrm{K}_{\mathrm{f}}$ is a constant relating to the adsorption capacity. While $1 / \mathrm{n}$ is related to the intensity of adsorption or surface heterogeneity, becoming more heterogeneous as its value gets closer to zero. A value of $1 / \mathrm{n}<1$ is indicative of a Langmuir isotherm, while $1 / \mathrm{n}>1$ indicates a cooperative adsorption ${ }^{19}$. $\mathrm{q}_{\mathrm{e}}$ is dye concentration at equilibrium onto biosorbent $\left(\mathrm{mg} \mathrm{g}^{-1}\right) . C_{e}$ is dye concentration at equilibrium in solution $\left(\mathrm{mg} \mathrm{l}^{-1}\right)$. The shape of the Langmuir isotherm can also be expressed in terms of separation factor $\left(\mathrm{R}_{\mathrm{L}}\right)$, which is given as follows ${ }^{20}$ :

$$
\mathrm{R}_{\mathrm{L}}=\frac{1}{1+\mathrm{K}_{\mathrm{L}} \cdot \mathrm{C}_{0}}
$$

where $\mathrm{K}_{\mathrm{L}}$ is Langmuir constant $\left(\mathrm{L} \mathrm{mg}^{-1}\right)$ related to the affinity of binding sites and the free energy of sorption and $\mathrm{C}_{0}$ is the initial concentration in the solution $\left(\mathrm{mg} \mathrm{L}^{-1}\right)$. For favorable adsorption, $0<\mathrm{R}_{\mathrm{L}}<1$, while $\mathrm{R}_{\mathrm{L}}>1$, $\mathrm{R}_{\mathrm{L}}=1$ and $\mathrm{R}_{\mathrm{L}}=0$ describe unfavorable, linear and irreversible adsorption, respectively.

\section{Results and discussion}

Surface proprieties and EDX analysis. Although the structure of biomaterials is mainly made from cellulose, hemicelluloses and lignin and are generally similar in structure, the type of functional groups and their acid and basic proprieties are different ${ }^{17,29}$. The acidic and basic surface groups were estimated after potentiometric titration measurements and the results are presented in Fig. 1.

It is obvious that the PP is acid, as the surface $\mathrm{pH}$ measurements confirmed the presence of more oxygenated surface groups. This result further confirmed the nature of the PP surfaces, which enhanced the adsorption of $\mathrm{CB}$ from the solution.

The elemental compositions were analyzed by EDX (energy dispersive X-ray microanalysis). Although the structure of biomaterials is mainly made from cellulose, hemicelluloses and lignin, which are generally similar in structure, the type of functional groups and their acid and basic properties are different. The Energy Dispersion Spectroscopy X (EDX) of potato powder (PP) presented in Fig. 2 shows the presence of different elements such as carbon, oxygen, sodium, potassium, etc. The two major elements detected in PP before adsorption process were carbon by weight ( $47.62 \%)$ and by atom (56.56\%), and oxygen by weight (45.71\%) and by atom ( $40.76 \%)$, as shown in the table of Fig. 2. It is clear that the proportions of carbon and oxygen are the highest, which confirms the organic nature of the adsorbent material.

Morphologic analysis. Several works were done to characterize the biolignocellulosic material by SEM for a better understanding of the physical-chemical and morphological characteristics ${ }^{30,31}$. The observation by 

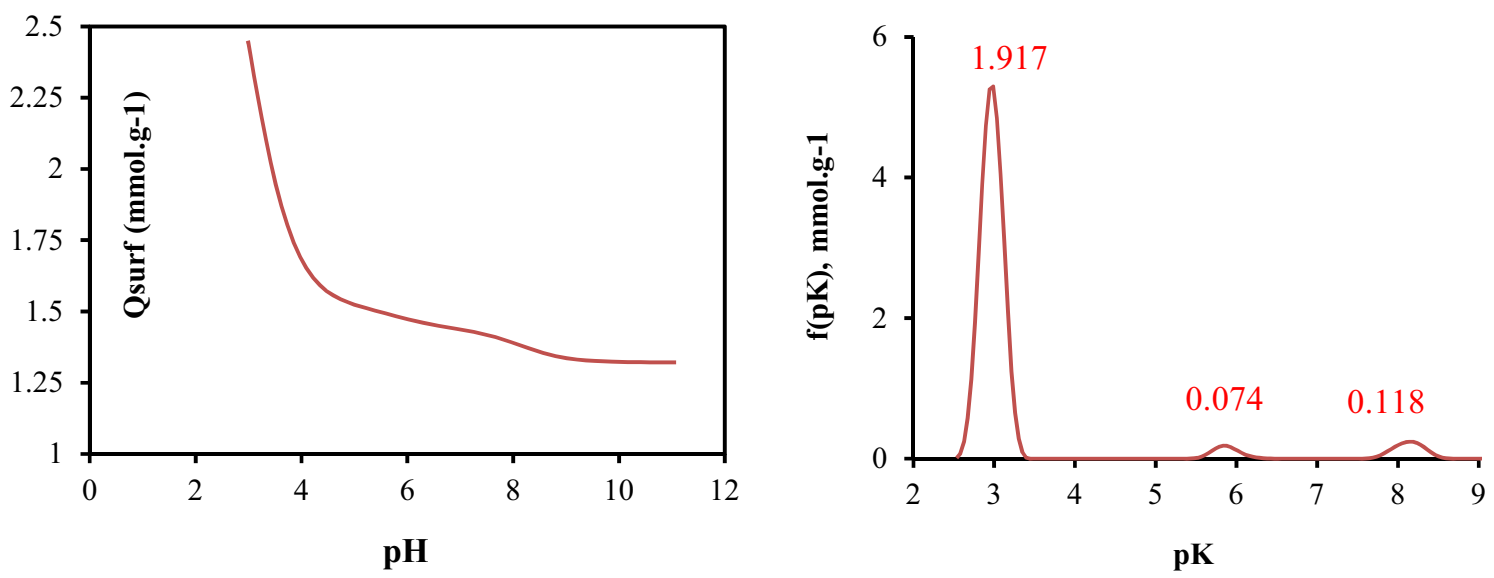

Figure 1. Potentiometric titration curve for PP.

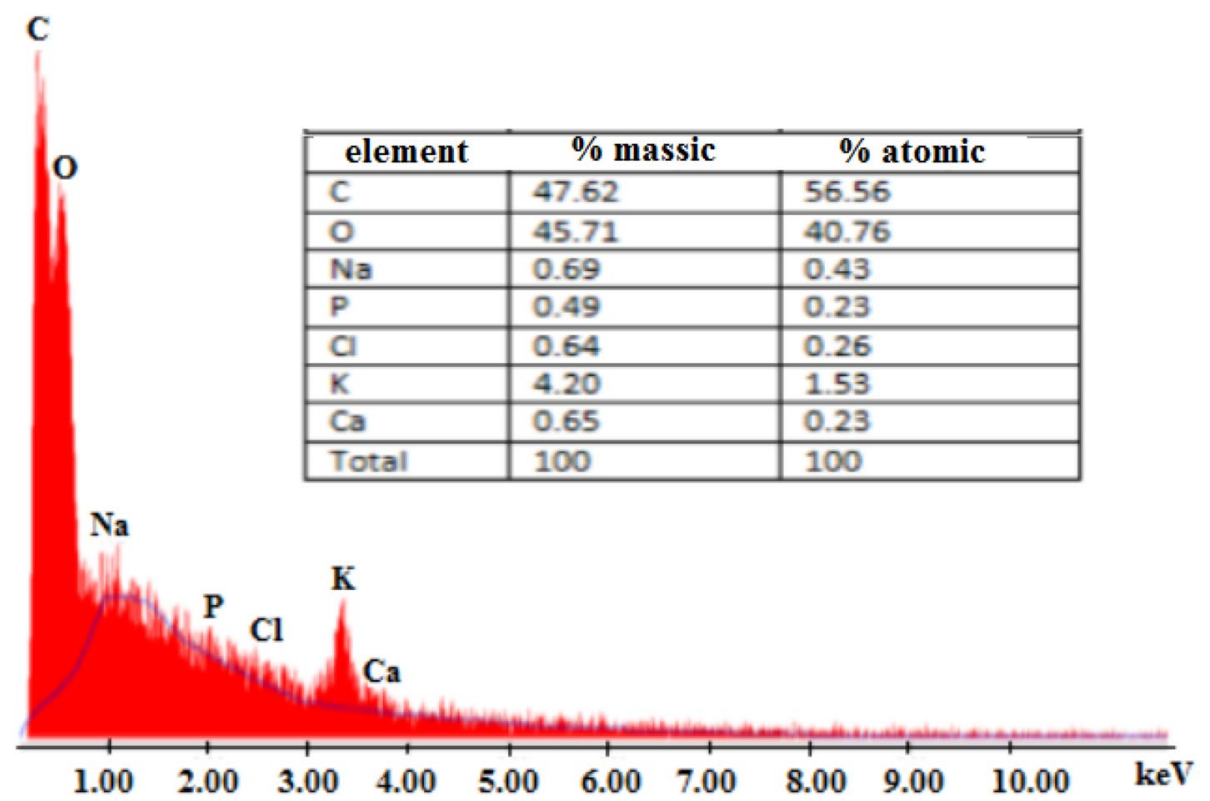

Figure 2. EDX spectrum and elemental analysis of potato powder (PP).

a scanning electron microscopy (SEM) (Fig. 3) shows micrograph of native and activated sorbents, where the pores in $\mathrm{PPa}$ are larger than in PP case.

While micrograph of active sorbent $(\mathrm{PPa})$ indicates that the external surface of the activated material displays a series of cavities with different dimensions for the material distributed over the surface. The micrograph of calcined sorbent (PPc), illustrates the surface morphology of the substrate after calcination. It clearly shows the presence of PPc nanotubes, which appear to be well ordered. This nanoporous structure can facilitate the anchoring and nucleation of the dyes on the PPc substrate.

Thermogravimetric analysis. For thermogravimetric analysis (TGA), $20 \mathrm{mg}$ of samples were introduced in a platinum sample holder and heated at a rate of $10^{\circ} / \mathrm{min}$ under air flow of $100 \mathrm{~mL} / \mathrm{min}$ up to $800{ }^{\circ} \mathrm{C}$ on a TGA92 instrument from Setaram (Lyon, France) $)^{1,2}$. The TG curve of the potato peels powder (PP) ( Fig. 4) shows a continuous weight loss at about $220^{\circ} \mathrm{C}$ related to moisture release (the loss of water), which is adsorbed both on the surface and in the pores of the sorbents. The second mass loss step in the temperature range 200$400{ }^{\circ} \mathrm{C}$ represents the decomposition of cellulose and Hemicellulose $\mathrm{e}^{21,22}$.

At temperatures higher than $400^{\circ} \mathrm{C}$, the loss of biomass may be indicative of lignin weight loss ${ }^{23}$. The TGA graphs were superimposed using the dry weight at $220^{\circ} \mathrm{C}$ as origin. This reveals that the mass loss due to lignin combustion increases as the mass of lost water decreases as illustrated in Table 2.

FTIR analysis. Infrared spectra were recorded using the $\mathrm{KBr}$ technique with a Mattson Genesis II spectrometer ${ }^{1-7}$. The spectra of potato peels powder were measured by an FT-IR spectrometer within the range $500-4000 \mathrm{~cm}^{-1}$ to determine the vibration frequency in the functional groups. The spectra of the native PP and 

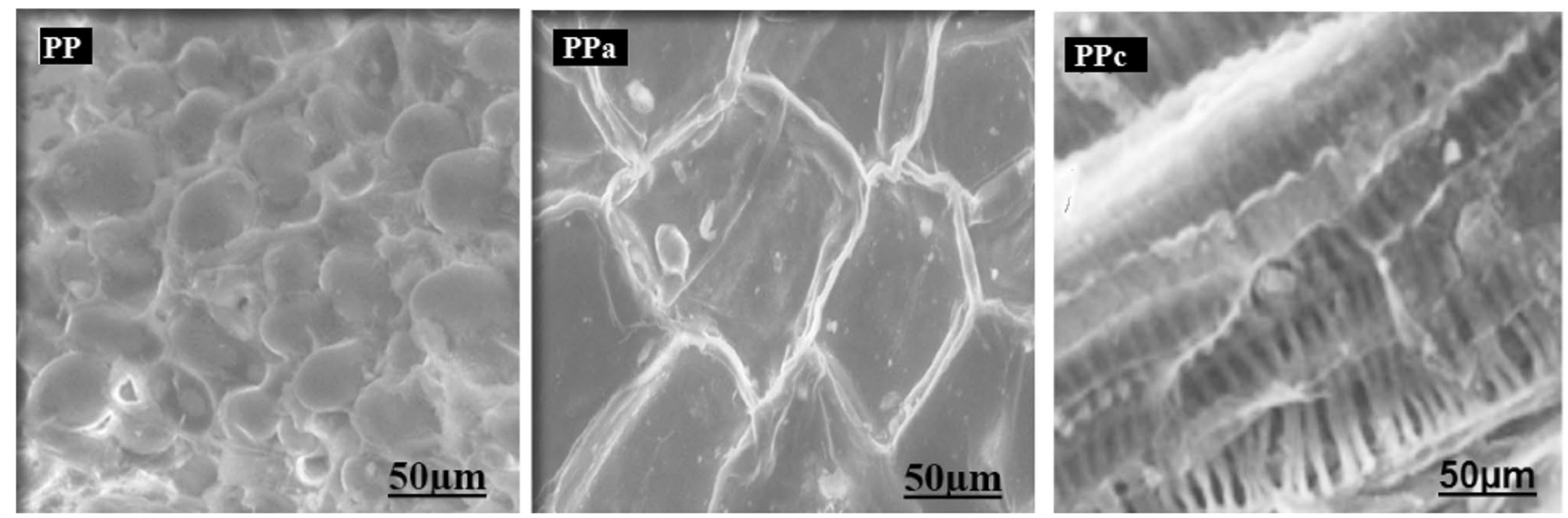

Figure 3. Scanning electron microscopy SEM micrographs of the native, activated and calcined material before treatment.

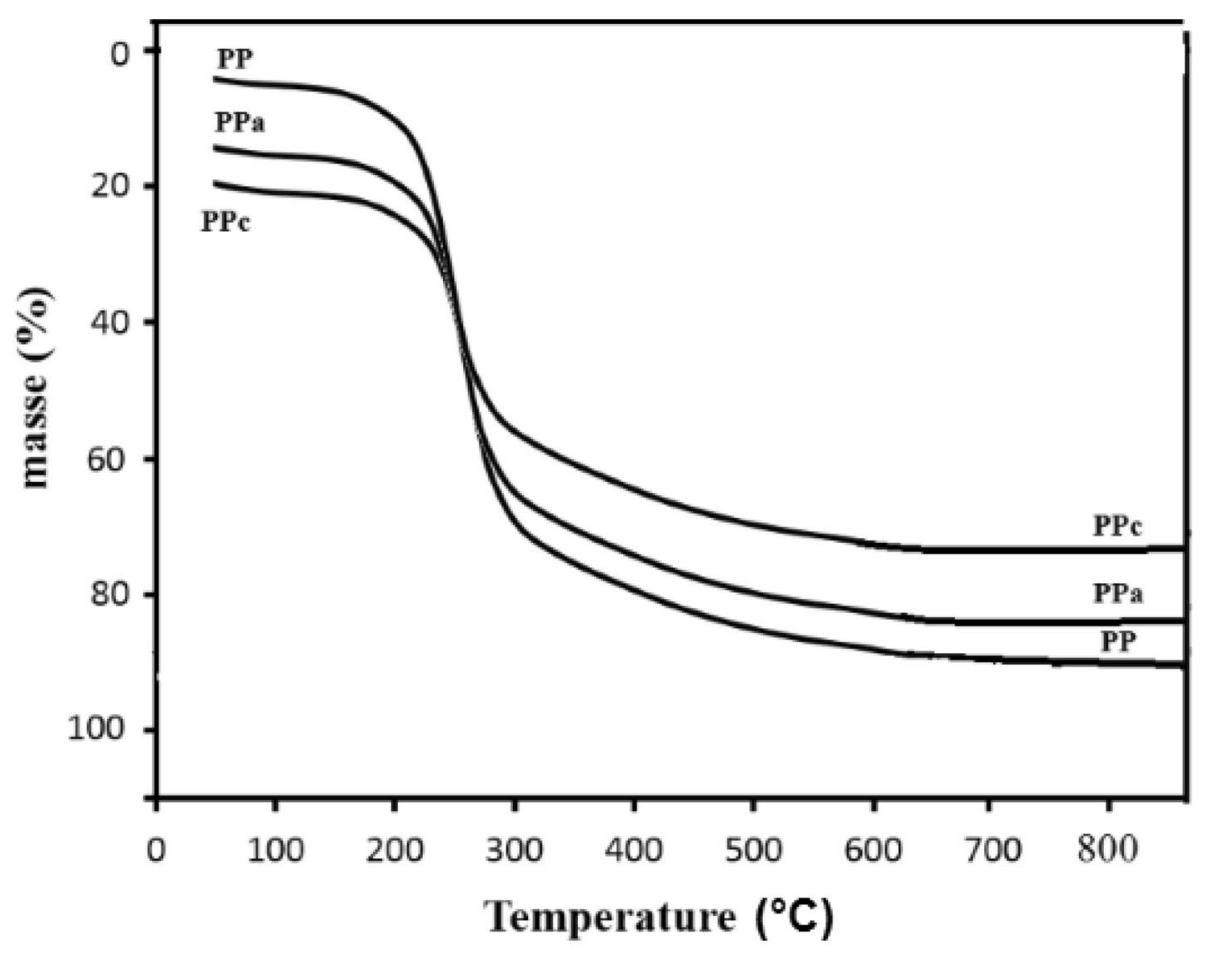

Figure 4. Thermogravimetric (TG) curve of the native, activated material and calcined material.

\begin{tabular}{|l|l|l|}
\hline Adsorbants & Mass loss lignin \% & Mass loss water \% \\
\hline $\mathrm{PP}$ & 90 & 5 \\
\hline $\mathrm{PPa}$ & 83 & 17 \\
\hline $\mathrm{PPc}$ & 73 & 20 \\
\hline
\end{tabular}

Table 2. Inverse relation between water contents and adsorbed lignin contents.

activated material PPa are quite similar (Fig. 5). In the high frequency region of the spectrum, bands at 3000$3600 \mathrm{~cm}^{-1}$, the tailing towards lower frequencies is due to $\mathrm{OH}$ stretching modes of $\mathrm{H}$ - bonded hydroxyl groups, while several weak bands between 2960 and $2850 \mathrm{~cm}^{-1}$ can be assigned to saturated $\mathrm{CH}$ stretching modes. The bands at $1600 \mathrm{~cm}^{-1}$ are the combination of $\mathrm{C}=\mathrm{C}$ stretching vibration of the aromatic ring structures and conju- 


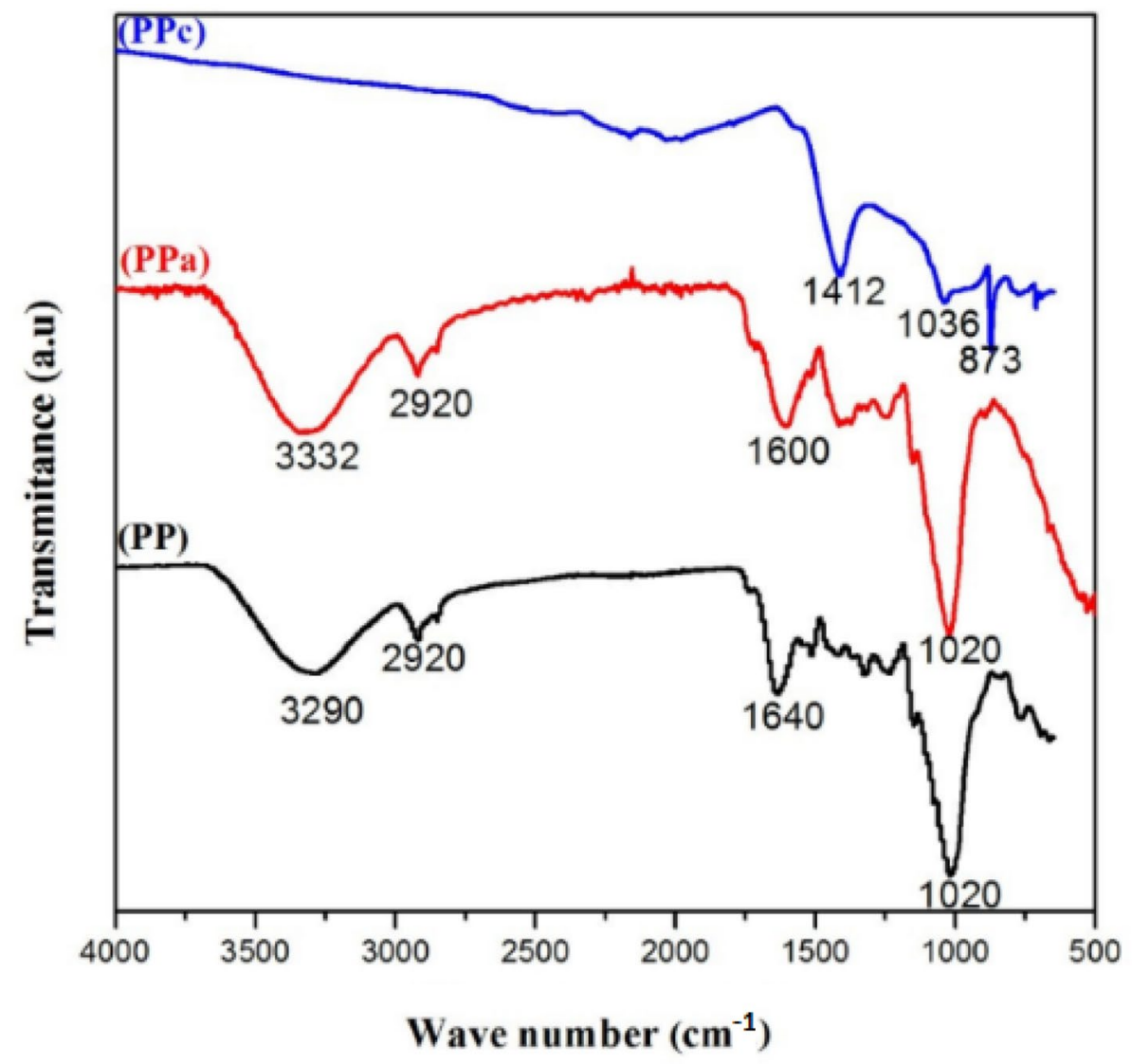

Figure 5. FTIR spectra analysis of native, activated and calcined materials.

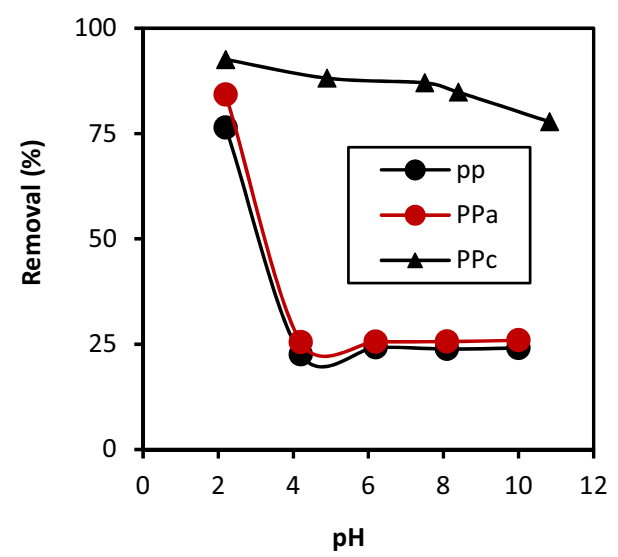

Figure 6. Effect of initial $\mathrm{pH}$ on $\mathrm{CB}$ adsorption of native, activated and calcined materials $\left(\mathrm{C}_{0}=30 \mathrm{mg} / \mathrm{L} ; \mathrm{m}\right.$ $\left.(\mathrm{PP})=\mathrm{m}(\mathrm{PPa})=2 \mathrm{~g} / \mathrm{L} ; \mathrm{m}(\mathrm{PPc})=0.6 \mathrm{~g} / \mathrm{L} ; \mathrm{T}=25 \pm 2{ }^{\circ} \mathrm{C}\right)$.

gated systems such as diketone, ketoester, quinone $\left(1550-1680 \mathrm{~cm}^{-1}\right)$. The adsorption bands between 1000 and $1050 \mathrm{~cm}^{-1}$ may result from vibrations that show bands at 1010 and $1020 \mathrm{~cm}^{-1}$ (C-O stretching).

The primary differences in the FTIR spectra of the activated carbons, after the pyrolysis at high temperature $\left(800{ }^{\circ} \mathrm{C}\right)$, are shown in the regions 1400 and $1040 \mathrm{~cm}^{-1}$. For PPc, the bands at $1412 \mathrm{~cm}^{-1}$ is due to the skeletal $(\mathrm{C}=\mathrm{C})$ vibrations of aromatic rings and the band $1036 \mathrm{~cm}^{-1}$ is assigned to $\mathrm{C}-\mathrm{O}-\mathrm{C}$ lactone structures (stretching C-O vibrations).

Effect of $\mathrm{pH}$. The $\mathrm{pH}$ plays an important role in the adsorption of any dye onto materials. Therefore, the first factor investigated in the present work is the effect of $\mathrm{pH}$ on $\mathrm{CB}$ removal. Figure 6 shows the aforementioned $\mathrm{pH}$ effect. The $\mathrm{CB}$ removal at strong acid $\mathrm{pH}$ values was found to be very large. The optimum $\mathrm{pH}$ for $\mathrm{CB}$ sorption by 


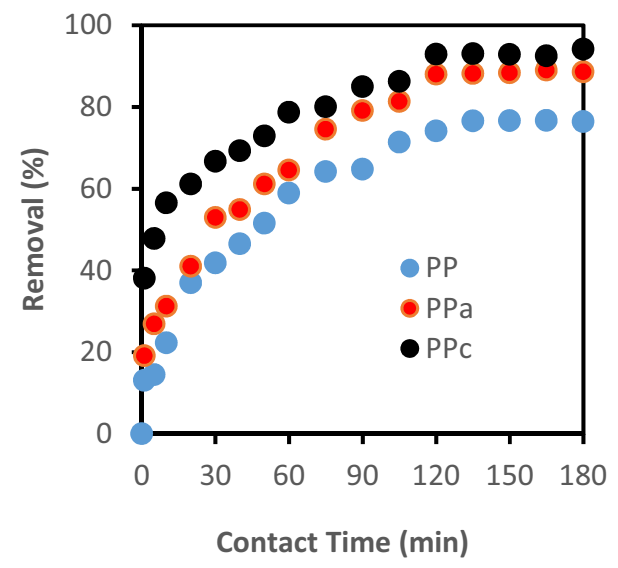

Figure 7. Effect of contact time on the sorption of $\mathrm{CB}$ onto native, activated and calcined sorbents at $\mathrm{pH}=2.2$ $\left(\mathrm{C}_{0}=30 \mathrm{mg} / \mathrm{L} ; \mathrm{m}(\mathrm{PP})=\mathrm{m}(\mathrm{PPa})=2 \mathrm{~g} / \mathrm{L} ; \mathrm{m}(\mathrm{PPc})=0.6 \mathrm{~g} / \mathrm{L} ; \mathrm{T}=25 \pm 2{ }^{\circ} \mathrm{C}\right)$.

\begin{tabular}{|c|c|c|c|c|c|c|c|}
\hline \multirow[b]{2}{*}{ Adsorbent } & \multirow[b]{2}{*}{ qe, $\exp \left(\mathrm{mg} \mathrm{g}^{-1}\right)$} & \multicolumn{3}{|c|}{ Pseudo-first-order model } & \multicolumn{3}{|c|}{ Pseudo-second-order model } \\
\hline & & qe, cal $\left(\mathrm{mg} \mathrm{g}^{-1}\right)$ & $k_{1}\left(\min ^{-1}\right)$ & $\mathbf{R}^{2}$ & qe, cal $\left(\mathrm{mg} \mathrm{g}^{-1}\right)$ & $\mathrm{k}_{2}\left(\mathrm{~g} \mathrm{mg}^{-1} \mathrm{mn}^{-1}\right)$ & $\mathbf{R}^{2}$ \\
\hline $\mathrm{PP}$ & 11.50 & 5.2456 & 0.0226 & 0.318 & 13.33 & 0.0027 & 0.985 \\
\hline $\mathrm{PPa}$ & 13.30 & 17.336 & 0.0820 & 0.753 & 15.015 & 0.0029 & 0.984 \\
\hline PPc & 47.00 & 27.05 & 0.0437 & 0.960 & 49.26 & 0.0018 & 0.993 \\
\hline
\end{tabular}

Table 3. Parameters of kinetic equations for the adsorption of CB onto PP, PPa and PPc.

all sorbents was 2.2 : (76.41, 84.26 and $92.6 \%$ for PP, PPa and PPc, respectively). At lower $\mathrm{pH}$, the surface of the adsorbent becomes more positive promoting electrostatic attraction activities between the negatively charged $\mathrm{SO}_{3}{ }^{-}$anion of the dye and the adsorbents. Except for PPc, as the $\mathrm{pH}$ increases from 2 to 10, there was a steady decrease in the amount of $\mathrm{CB}$ being adsorbed, revealing thereby that PPc was acidic in the $\mathrm{pH}$ range 2-10. There was little effect on the removal of $\mathrm{CB}$ in the range of 2.2 to ambient $\mathrm{pH}(92.6 \%$ at $\mathrm{pH} 2.2$ to $86.3 \%$ at $\mathrm{pH} 7.5)$. This suggests that $\mathrm{CB}$ molecules are not adsorbed through the ionic $\mathrm{SO}_{3}{ }^{-}$groups ${ }^{24}$. Hence, the ambient $\mathrm{pH}$ was chosen for the study of CB sorption isotherm on PPc. This result does not agree with that reported by Kyzas ${ }^{25}$, where the carbonization of potato peels at $800^{\circ} \mathrm{C}$ caused a collapse in the texture of the activated carbon prepared. The total elimination for PPc is observed for a capacity of $46.3 \mathrm{mg} \mathrm{g}^{-1}$ at fixed equilibrium time $(2 \mathrm{~h})$. Furthermore, unlike the native material (PP), elimination is partial; we obtain an adsorption capacity of $11.46 \mathrm{mg} \mathrm{g}^{-1}$.

Kinetic studies. Experimental kinetic data for adsorption of CB onto native PP and activated (PPa, PPc) adsorbents for a $30 \mathrm{mg} \mathrm{L}^{-1}$ dye solution, at $\mathrm{pH} 2.2$ are illustrated in Fig. 7. The total elimination at equilibrium adsorption time $(180 \mathrm{mn})$, is $94 \%, 88.6 \%$ and $76.41 \%$ for $\mathrm{PPc}, \mathrm{PPa}$ and $\mathrm{PP}$ respectively. Two simplified kinetic models including pseudo- first-order and pseudo-second-order equations were used in this study.

The results of the kinetic parameters based on the values of the correlation coefficients $\mathrm{R}^{2}$ are shown in Table 3. The data fit better with the second order kinetic model than with the pseudo first order for the three adsorbents. Thus, the adsorption rate is influenced by the availability of the adsorption sites rather than by the concentration of the dye in the solution ${ }^{26}$.

The $\mathrm{q}_{\mathrm{e}}$ values for PP, $\mathrm{PPa}$ and PPc obtained from the pseudo-second-order rate model were in better agreement with qe (exp) values compared to those obtained from the pseudo-first-order rate model. The pseudo second order kinetic model is based on the assumption that the rate-controlling step may be a chemisorption involving valence forces through sharing or exchange of electrons between biosorbent and sorbate ${ }^{27}$.

Sorption isotherms modeling. The adsorption isotherms of synthetic aqueous solutions of CB on PP, $\mathrm{PPa}$ and PPc at variable initial concentrations of dye is displayed (Fig. 8). According to the classification of Giles and $\mathrm{Col}^{28}$, the adsorption isotherms of the CB dye are of type L. The comparison of the adsorption capacities is of the following order $(\mathrm{PPc}>\mathrm{Ppa}>\mathrm{PP})$. The isotherms follow Langmuir's model perfectly. Therefore, the attraction forces between the adsorbed molecules are $\operatorname{low}^{28}$. The experimental data of adsorption equilibrium were tested by means of the Langmuir (type I, type II) and Freundlich isotherms. Based on the corresponding correlation coefficient $\mathrm{R}^{2}$ values and the adsorption capacity estimated by the models shown in Table 4 , it was found that the Langmuir II model gives the best fit for all the sorbents. The value of $1 / \mathrm{n}$ is within the limit range of validity of (0.3-0.5), and this confirms that the isotherm is of type L. 


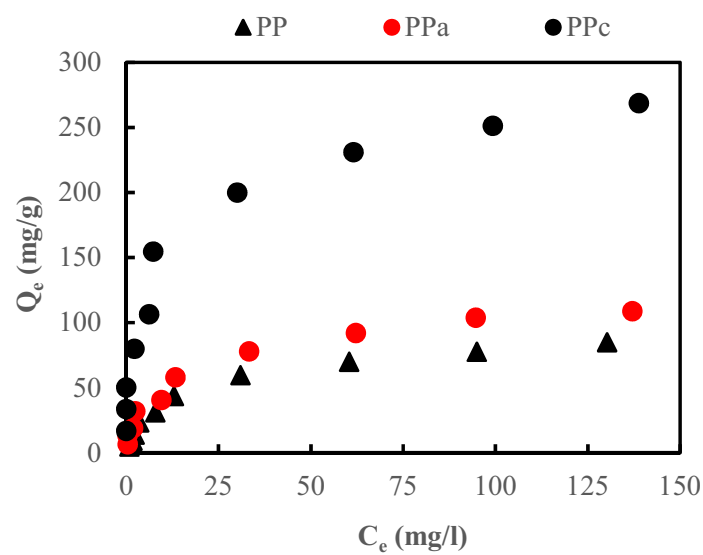

Figure 8. Sorption isotherms of $\mathrm{CB}$ for the native and modified sorbents $(\mathrm{m}(\mathrm{PP})=\mathrm{m}(\mathrm{PPa})=2 \mathrm{~g} / \mathrm{L} ; \mathrm{m}$ $(\mathrm{PPc})=0.6 \mathrm{~g} / \mathrm{L} ; \mathrm{pH}=2.2)$.

\begin{tabular}{|c|c|c|c|c|}
\hline Isotherm model & \multicolumn{4}{|l|}{ Parameters } \\
\hline Langmuir I & $\mathbf{q}_{\exp }$ & $\mathbf{q}_{\text {th }}$ & $\mathrm{K}_{\mathrm{L}}\left(\mathrm{L} \mathrm{mg}^{-1}\right)$ & $\mathbf{R}^{2}$ \\
\hline PP & 85.0 & 125.0 & 0.048 & 0.990 \\
\hline $\mathrm{PPa}$ & 108.6 & 58.8 & 0.460 & 0.976 \\
\hline $\mathrm{PPc}$ & 268.5 & 238.1 & 0.211 & 0.921 \\
\hline Isotherm model & \multicolumn{4}{|l|}{ Parameters } \\
\hline Langmuir II & $\mathbf{q}_{\exp }$ & $\mathbf{q}_{\text {th }}$ & $\mathrm{K}_{\mathrm{L}}\left(\mathrm{L} \mathbf{~ m g}^{-1}\right)$ & $\mathbf{R}^{2}$ \\
\hline $\mathrm{PP}$ & 85.0 & 100.0 & 0.063 & 0.996 \\
\hline $\mathrm{PPa}$ & 108.6 & 125.0 & 0.088 & 0.990 \\
\hline $\mathrm{PPc}$ & 268.5 & 270.3 & 0.215 & 0.992 \\
\hline Isotherm model & \multicolumn{3}{|l|}{ Parameters } & \\
\hline Freundlich & $\mathrm{K}_{\mathrm{f}}\left(\mathrm{mg} \mathrm{g}^{-1}\right)$ & $1 / n$ & $\mathbf{R}^{2}$ & \\
\hline $\mathrm{PP}$ & 2.504 & 0.531 & 0.924 & \\
\hline $\mathrm{PPa}$ & 3.257 & 0.427 & 0.932 & \\
\hline PPc & 70.360 & 0.284 & 0.936 & \\
\hline
\end{tabular}

Table 4. Parameters for different adsorption isotherm models $(m(P P)=m(P P a)=2 \mathrm{~g} / \mathrm{L}, \mathrm{m}(\mathrm{PPc})=0.6 \mathrm{~g} / \mathrm{L}$; $\mathrm{pH}=2.2$ ).

Considering the effect of calcinations (carbonization), PPc exhibits the best adsorption capacity and the higher value of $\mathrm{K}_{\mathrm{L}}$, compared to the other biomaterial according to Langmuir II. The maximum sorption capacity $\mathrm{q}_{\max }$ of CB dye is $270.3 \mathrm{mg} \mathrm{g}^{-1}$; the high value of Langmuir constant $\mathrm{K}_{\mathrm{L}}\left(0.215 \mathrm{~L} \mathrm{mg}^{-1}\right)$ suggests a strong bonding of the $\mathrm{CB}$ dye due to the adsorption free energy and the specific adsorbent affinity. Its value is the reciprocal of the $\mathrm{CB}$ dye concentration at which half of the saturation of the adsorbent is attained.

\section{Conclusion}

The adsorption experiments indicated that Waste Potato Peels Powder (PPc) calcined at $800{ }^{\circ} \mathrm{C}$ was effective in removing greater than $94 \%$ of $\mathrm{CB}$ dye from aqueous solution within $180 \mathrm{~min}$ at $\mathrm{pH}=2.2$. The kinetics of adsorption conformed to a pseudo-second-order model indicating a chemisorption adsorption process. Isotherm studies were well described by the Langmuir, confirming the single-layer, homogeneous and chimisorption adsorption process. The experimental results have shown that PPc $\left(270.3 \mathrm{mg} \mathrm{g}^{-1}\right)$ has a greater capacity compared to $\mathrm{pp}\left(100 \mathrm{mg} \mathrm{g}^{-1}\right)$ and $\mathrm{ppa}\left(125 \mathrm{mg} \mathrm{g}^{-1}\right)$. Physical activation of sorbent Waste Potato Peels Powder results in enhanced sorption capacity for CB.

Therefore, Waste Potato Peels Powder is a low cost, eco-friendly and a potential alternative adsorbent to high cost commercial adsorbents for the treatment of dye-contaminated wastewater.

The drawback of the given processes is the high sludge production formed for Wastewater treatment. Sludge treatment has become one of the most important environmental issues. Thus, the use of biochar as an addition to sewage sludge can be a new and interesting solution in future utilization of sewage sludge.

Received: 27 July 2020; Accepted: 17 November 2020

Published online: 22 January 2021 


\section{References}

1. Lemlikchi, W., Sharrock, P., Mecherri, M. O. \& Fiallo, M. An elimination of disperse red 167 from a textile dye effluent with natural Hydroxyapatite. Int. J. Mat. Eng Tech. 6, 111-124 (2011).

2. Lemlikchi, W., Fiallo, M., Sharrock, P., Nzihou, A. \& Mecherri, M. O. Treatment of textile waste waters by hydroxyapatite co- precipitation with adsorbent regeneration and reuse. Waste Biomass Valor. 3, 75-79 (2012).

3. Lemlikchi, W., Sharrock, P., Mecherri, M. O., Fiallo, M. \& Nzihou, A. Reaction of calcium phosphate with textile dyes for purification of wastewaters. J. Desal Water Treatment. 52, 1669-1673 (2014).

4. Lemlikchi, W., Sharrock, P., Fiallo, M., Nzihou, A. \& Mecherri, M. O. Hydroxyapatite and alizarin sulfonate ARS modeling interations for textile dyes removal. Proc. Eng. 83, 378-385 (2014).

5. Lemlikchi, W. et al. Kinetic study of the adsorption of textile dyes on synthetic hydroxyapatite in aqueous Solution. J. Ind. Eng. Chem. 32, 233-237 (2015).

6. Oubagha, N., Lemlikchi, W., Sharrock, P., Fiallo, M. \& Mecherri, M. O. Hydroxyapatite precipitation with Hydron Blue dye. J. Environ. Manag. 203, 807-810 (2017).

7. Lemlikchi, W., Drouiche, N., Baaziz, B. \& Mecherri, M. O. Formation of mixed complexes of type phosphate-ca-dye. J. Separ. Sci. Tech. 50, 2676-2679 (2015).

8. Lemlikchi, W., Khaldi, S., Mecherri, M. O., Lounici, H. \& Drouiche, N. Degradation of disperse red 167 Azo Dye by bipolar electrocoagulation. J. Separ. Sci. Tech. 47, 1682-1688 (2012).

9. Finkbeiner, P. et al. Understanding the potential for selective natural organic matter removal by ion exchange. Water Res. 146, 256-263 (2018).

10. Tahir, M. A., Bhatti, H. N., Hussain, I., Bhatti, I. A. \& Asghar, M. Sol-gel synthesis of mesoporous silica-iron composite: kinetics, equilibrium and thermodynamics studies for the adsorption of turquoise-blue X-GB dye. Z. Phys. Chem. 234, 233-253 (2020).

11. Haq, N. B. et al. Efficient removal of dyes using carboxymethyl cellulose/alginate/polyvinyl alcohol/rice husk composite: Adsorption/desorption, kinetics and recycling studies. Int. J. Biol. Mach. 150, 861-870 (2020).

12. Saima, N., Haq, N. B., Munawar, I., Fida, H. \& Fazli, M. S. Chitosan, starch, polyaniline and polypyrrole biocomposite with sugarcane bagasse for the efficient removal of Acid Black dye. Int. J. Bio. Mach. 147, 439-452 (2020).

13. Tahir, M. A., Bhatti, H. N., Hussain, I., Bhatti, I. A. \& Asghar, M. Sol-gel synthesis of mesoporous silica-iron composite: kinetics, equilibrium and thermodynamics studies for the adsorption of turquoise-blue X-GB dye. Z. Phys. Chem. 234, 233-253 (2019).

14. Urooj, K., Haq, N. B., Munawar, I., Saba, J. \& Muhammad, Z. Biogenic synthesis, characterization and investigation of photocatalytic and antimicrobial activity of manganese nanoparticles synthesized from Cinnamomum verum bark extract. J. Mol. Struct. 1179, 532-539 (2019).

15. Wu, F. C., Tseng, R. L. \& Juang, R. S. Comparative adsorption of metal and dye on flake-and bead-types of chitosans prepared from fishery wastes. J. Hazard. Mat. 73, 63-75 (2000).

16. Lagergren, S. K. About the theory of so-called adsorption of soluble substances. Sven. Vetenskapsakad Handingarl. 24, 1-39 (1898).

17. Ho, Y. S., Ng, J. C. Y. \& McKay, G. Kinetics of pollutant sorption by biosorbents. Separ. Purific. Meth. 29, 189-232 (2000).

18. Langmuir, I. The constitution and fundamental properties of solids and liquids Part I Solids. J. Am. Chem. Soc. 38, 2221-2295 (1916).

19. Mandal, A., Singh, N. \& Nain, L. Agro-waste biosorbents: Effect of physico-chemical properties on atrazine and imidacloprid Sorption. J. Environ. Sci. Health. 52, 671-682 (2017).

20. El Nemr, A., Abdelwahab, O., El-Sikaily, A. \& Khaled, A. Removal of direct blue- 86 from aqueous solution by new activated carbon developed from orange peel. J. Hazard. Mat. 161, 102-110 (2009).

21. Gao, Y. et al. Comparisons of porous, surface chemistry and adsorption properties of carbon derived from Enteromorpha prolifera activated by $\mathrm{H}_{4} \mathrm{P}_{2} \mathrm{O}_{7}$ and $\mathrm{KOH}$. Chem. Eng. J. 232, 582-590 (2013).

22. Liu, D. et al. Facile preparation of hierarchically porous carbon using diatomite as both template and catalyst and methylene blue adsorption of carbon products. J. Coll. Interface Sci. 388, 176-184 (2012).

23. Roman, S. et al. Production of low-cost adsorbents with tunable surface chemistry by conjunction of hydrothermal carbonization and activation processes. Microp. Mesopor. Mat. 165, 127-133 (2013).

24. Jafari, S., Yahyaei, B., Kusiak-Nejman, E. \& Sillanpää, M. The influence of carbonization temperature on the modification of TiO ${ }_{2}$ in the removal of methyl orange from aqueous solution by adsorption. Desal. Water Treat. 57, 18825-18835 (2016).

25. Kyzas, G.Z., Deliyanni, E.A., Matis, K.A. Activated carbons produced by pyrolysis of waste potato peels: cobalt ions removal by adsorption. Coll. Surf. A: Physicochem. Eng. Aspects. 490, 74-83 (2016).

26. Heibati, B. et al. Removal of noxious dye - Acid Orange 7 from aqueous solution using natural pumice and Fe-coated pumice Stone. J. Ind. Eng. Chem. 31, 124-131 (2015).

27. Velazquez-Jimenez, L. H., Pavlick, A. \& Rangel-Mendez, J. R. Chemical characterization of raw and treated agave bagasse and its potential as adsorbent of metal cations from water. Ind. Crops Products. 43, 200-206 (2013).

28. Gilles, C.H., Mc Evant, M., Nakhawas, S.W. \& Smith, D.J. Studies in Adsorption. Part XI.* A System of Classification of Solution Adsorption Isotherms, and its Use in Diagnosis of Adsorption Mechanisms and in Measurement of Specific Surface Areas of Solids. J. Chem. Soc. 786, 3973-3990 (1960).

29. Gisi, S.D., Lufrano, G., Grassi, M., Notarnicola, M. Characteristics and adsorption capacities of low-cost sorbents for wastewater Treatment. A review, Sustain. Mat. Technol. 9, 1-40 (2016).

30. Sandra, C. P., Larissa, M., Cristina, M. M. M. \& Cristiane, S. F. Physical-chemical-morphological characterization of the whole sugarcane lignocellulosic biomass used for $2 \mathrm{G}$ ethanol production by spectroscopy and microscopy techniques. Renew. Energy. 87, 607-617 (2016).

31. Zhao, H. et al. Studying cellulose fiber structure by SEM, XRD NMR and acid hydrolysis. Carbohydr. Polym. 68, 235-241 (2007).

\section{Acknowledgements}

The authors appreciate the effort of the management of Tizi-Ouzou University of Algeria, for providing the Laboratory of applied chemistry and chemical engineering with the necessary equipment to carry out this research work. In addition, we would like thank Pr. Samuel MIGNARD for his help in the FTIR, SEM and pyrolysis analyses (Institute of Chemistry of Environments and Materials (IC2MP) of Poitiers France).

\section{Author contributions}

K.B. drafted the main manuscript text, W.L. drew the Chemical structure of Cibacron blue CB and reviewed the manuscript, A.F. writing manuscript, S.M. designed the research.

\section{Competing interests}

The authors declare no competing interests. 


\section{Additional information}

Correspondence and requests for materials should be addressed to W.L. or A.F.

Reprints and permissions information is available at www.nature.com/reprints.

Publisher's note Springer Nature remains neutral with regard to jurisdictional claims in published maps and institutional affiliations.

(c) (1) Open Access This article is licensed under a Creative Commons Attribution 4.0 International License, which permits use, sharing, adaptation, distribution and reproduction in any medium or format, as long as you give appropriate credit to the original author(s) and the source, provide a link to the Creative Commons licence, and indicate if changes were made. The images or other third party material in this article are included in the article's Creative Commons licence, unless indicated otherwise in a credit line to the material. If material is not included in the article's Creative Commons licence and your intended use is not permitted by statutory regulation or exceeds the permitted use, you will need to obtain permission directly from the copyright holder. To view a copy of this licence, visit http://creativecommons.org/licenses/by/4.0/.

(C) The Author(s) 2021 